\title{
Comparison of aeroallergen sensitization patterns in the United States and Europe
}

\author{
Luca Conti, Kelly Gatt, Christopher Zammit, Stephen Montefort, David Bilocca \\ Respiratory Department, Mater Dei Hospital, Malta
}

\begin{abstract}
The global prevalence of allergic diseases has increased considerably and they represent a major socio-economic burden. Asthma is a complex disease and understanding asthma phenotypes and endotypes could eventually lead to individualized management, and offer better symptom control and quality of life. In this review, we first summarize the pathogenesis of atopic asthma and delve into the assessment of sensitization to aeroallergens through skin prick testing and serological testing with total and specific immunoglobulin E testing. We will then analyze the distribution of aeroallergen sensitization patterns in the United States and Europe and its effect on the population. This review gives a comprehensive overview on atopy and it compares the prevalence and effect of atopy within various regions of both continents using data from large multicenter studies. We will conclude this review by discussing the efficacy of add-on treatments in the most prevalent severe asthma phenotypes and endotypes.
\end{abstract}

\section{Introduction}

There has been an increased prevalence of allergic diseases, such as asthma and rhinitis over the recent decades, ${ }^{1}$ which has led to significant social and economic consequences. ${ }^{2}$ Asthma is a complex disease, with a variable presentation depending on the underlying pathophysiology. Several different asthma phenotypes have been described in the literature, based on the clinical, physiological, biochemical, and morphological characteristics. Whereas asthma phenotype

\footnotetext{
Correspondence: Luca Conti, Respiratory Department, Mater Dei Hospital, Birkirkara Bypass, Malta. Tel.: +356.2545.0000. E-mail: lucaconti91@gmail.com
}

Key words: Aeroallergen; atopy; asthma; immunoglobulin E; skin prick testing.

Contributors: $\mathrm{LC}, \mathrm{KG}$, literature review, writing and revising the manuscript; $\mathrm{CZ}, \mathrm{SM}, \mathrm{DB}$, literature review and revising the manuscript.

Conflict of interests: the authors declare no potential conflict of interests.

Received for publication: 8 June 2019.

Revision received: 14 July 2019.

Accepted for publication: 19 August 2019.

This work is licensed under a Creative Commons Attribution NonCommercial 4.0 License (CC BY-NC 4.0).

${ }^{\circ}$ Copyright: the Author(s), 2019

Licensee PAGEPress, Italy

Italian Journal of Medicine 2019; 13:225-233

doi:10.4081/itjm.2019.1189 characteristics relate to observable characteristics, asthma endotypes related to the underlying pathophysiological mechanism. ${ }^{3}$ Despite considerable advances in the understanding and management of asthma, there are many unanswered questions regarding the underlying mechanisms of these disease subgroups, which hinders drug development. The classification of asthma phenotypes and endotypes has already led to novel and successfully targeted existing treatments, hence improving asthma care. ${ }^{4}$

\section{Pathophysiology}

The identification of immunoglobulin E (IgE), the hallmark of type 1 hypersensitivity, represented a major breakthrough in allergy and asthma research in 1966. IgE plays a central role in the pathophysiology of allergic diseases. Raised total IgE levels have been associated with 3 main asthmatic phenotypes: allergic (or atopic) asthma, allergic bronchopulmonary aspergillosis, hyper-eosinophilic asthma associated with nasal polyposis and $S$. aureus colonization.

Atopic asthma is genetically determined ${ }^{5}$ and its pathogenesis is characterized by a persistent T-helper (Th)2-type driven inflammatory response upon exposure to specific inhaled allergens. ${ }^{6,7}$ An allergen is an environmental antigen which is able to induce specific $\mathrm{IgE}$ antibody production. Although aeroallergens play a pivotal role in the allergic cascade, environmental factors including Staphylococcus aureus, viruses and air pollution act as co-factors promoting epithelial activation and allergen modification. ${ }^{5}$

In susceptible individuals, the aeroallergens deposit on the epithelium of the trachea, bronchi or alveoli, which cause activation of the epithelium with 
subsequent upregulation and recruitment of the primary antigen presenting cells, the dendritic cell. Dendritic cells present allergens to CD4+ T-cells, inducing (Th) 2 cells to produce an immune response with production of specific $\operatorname{IgE}$ antibodies. (Th) 2 cells express cytokines including interleukin (IL)-4, IL-5 and IL$13 .{ }^{8} \mathrm{IL}-4$ promotes (Th) 2 cell development and B-cell class-switch recombination from IgM to IgE upon activation by IL-4 and/or IL-13. Class-switch recombination to $\operatorname{IgE}$ is also seen in type 2 innate lymphoid cells (ILC2s). ${ }^{5}$ IL-4 and IL-13 affect the epithelium by chemokine production, including eotaxin, IL- 8 , and monocyte chemoattractant protein. Activated (Th) 2 cells also produce high amounts of IL-5 and IL-13. IL13 leads to goblet cell hyperplasia and mucus hypersecretion, with subsequent smooth muscle hypertrophy, subepithelial fibrosis, and airway hyperresponsiveness. ${ }^{9,10} \mathrm{IL}-5$ plays a pivotal role in mediating eosinophil recruitment, maturation and prolonged survival in response to aeroallergen stimuli. It also promotes upregulation and differentiation of eosinophil progenitors in the bone marrow. ${ }^{11}$ Mast cells, (Th) 2 cells and ILC2 cells, secrete IL-9, which stimulates and promotes proliferation of activated $\mathrm{T}$ cells and mast cells. It also upregulates IgE production by $B$ cells and increased cell surface expression of the high-affinity IgE receptor FceRI to respond to allergens. Mast cells secrete pro-inflammatory mediators (histamine, prostaglandin D2 and leukotrienes, platelet activating factor and other mediators) increasing vascular permeability leading to bronchial edema, bronchoconstriction and inflammation. ${ }^{12}$

On allergen re-exposure, the allergen causes FceRI cross-linking on tissue mast cells and basophils leading to a cascade of intracellular events precipitating IgE-driven cell activation and degranulation. ${ }^{5}$ After exposure to specific aeroallergens, the number of eosinophils increase due to two main reasons: an early-phase response secondary to mast cell degranulation $^{13}$ and a late-phase response, which occurs after cell recruitment from the circulation (eosinophils, basophils and T cells). ${ }^{14}$ Eosinophils produce a variety of chemokines and cytokines triggering epithelial damage and bronchial hyperresponsiveness. ${ }^{8}$

Serological testing and/or skin-prick testing (SPT) are used in patients with atopic asthma to determine the presence of specific IgE, as it is a key feature of this phenotype. Blood eosinophilia may be present in conjunction with atopic asthma and it is found in other atopy-related disorders, such as allergic rhinitis and atopic dermatitis. ${ }^{5}$

\section{Skin prick testing}

Skin prick testing is a reliable method to assess IgEmediated sensitization to aeroallergens in patients with atopic asthma. It is a cheap, reproducible, fairly rapid minimally invasive test, which is readily available to accurately identify the causative aeroallergen on a suspected type 1 mediated hypersensitivity reactions. ${ }^{15-18}$

SPT is recommended as a result of the high degree of correlation with symptomatology, and it utilizes the presence and degree of cutaneous reactivity to an allergen as a marker for sensitization. SPTs offer high sensitivity (80-97\%) and specificity (70-95\%) to diagnose aeroallergens. ${ }^{15,16}$

In the case of asthmatic patients, SPTs should be performed when asthmatic symptoms are controlled and if peak flow is less than 70\% predicted, SPT is relatively contraindicated. Prior to performing SPTs, the expiry date of the allergen solutions should be checked and ensure they are adequately stored at $+2^{\circ} \mathrm{C}$ to $+8^{\circ} \mathrm{C}$ when not utilized. A drug history is vital as certain medication, such as antihistamines, may interfere with proper interpretation of the final results, e.g. a second generation $\mathrm{H} 1$-blocker should be stopped 7 days prior SPT. Other medications, which are not necessarily used for the treatment of allergic disease, such as the anxiolytic imipramine or phenothiazine antipsychotics may also interfere with interpretation. The volar aspect of the forearm is used for SPT using either a test grid or a grid marked with a pen. A drop of each standardized allergen extract, including the positive and negative control should be applied at least $2 \mathrm{~cm}$ apart, to avoid false-positive reactions due to contamination. The drop should be immediately pricked with a new single-head metal lancet for each allergen for at least 1 second, with equal pressure applied. Penetrating the epithelial layer may cause bleeding and thus may lead to a false-positive result. Any excess allergen extract solution can be blotted using a clean tissue. Cutaneous reactivity should be tested after 15-20 min following application. ${ }^{16}$

The positive and negative controls should be identified and measured first. A positive result is expected with histamine dihydrochloride $0.1 \%$, unless the patient had been on treatment affecting the outcome. The patient is evaluated for dermographism with the negative control. A test is regarded as positive if the value of the longest diameter is $\geq 3 \mathrm{~mm}$. A permanent record of the SPT could be performed by outlining the wheal with a pen and using cellophane tape to produce a negative. ${ }^{16}$

SPT confirms allergen sensitization, but in order to assess atopy to a specific aeroallergen, its clinical relevance must be appropriately interpreted based on symptomatology, past medical history and other investigations such as specific IgE serological testing. ${ }^{15-18}$

Various population-based studies and multicenter studies have been conducted over the recent decades, namely the European Community Respiratory Health Survey (ECRHS), National Health and Nutrition Examination Surveys (NHANES), International Study of 
Asthma and Allergies in Childhood (ISAAC), and the Global Allergy and Asthma European Network (GA2 LEN) skin test study I and II. These studies have shown that aeroallergen sensitization varies between a geographical area and another, depending on exposure rates. Geographical and seasonal variations in aeroallergen sensitization may possibly be attributed to increasing human migration and rapid urbanization as well as climate change caused by pollution. ${ }^{19}$ Changes in aeroallergen sensitization patterns have also been observed over time. ${ }^{20}$

No standard consensus protocol for SPT was available in Europe up until the last few years. A study conducted by the $\mathrm{GA}^{2} \mathrm{LEN}$ network showed that despite there being similarities in technique of SPT throughout the 29 allergy centers, procedures varied across Europe. ${ }^{21}$ This call for standardization was followed up with the introduction of the GA ${ }^{2} \mathrm{LEN}$ protocol, which recommended a common panel of aeroallergens in order to harmonize operating procedures throughout the European centers. It also standardized the method of procedure to perform and interpret the SPT results based on published guidelines, The European Academy of Allergy and Clinical Immunology (EAACI) position paper, the Nordic Standards and the ISAAC phase II protocol. The Pan-European allergen battery (Table 1) was proven and tested in a large multicenter study involving 17 allergy centers across 14 European countries, the GA ${ }^{2} \mathrm{LEN}$ skin test study I and II.

In the United States of America (USA), prevalence of aeroallergen sensitization in the general population was estimated in 3 NHANES, 2 of which, NHANES II, conducted in the late 1970 s and III, ${ }^{22}$ conducted in the late $1980 \mathrm{~s}$, were conducted by SPTs. NHANES 2005-2006 ${ }^{23}$ measured serum total IgE and specific IgE levels within the general population. The standard prick test panel tested for in the NHANES III is shown in Table 2.

\section{Indoor allergens}

Der p1 (Dermatophagoides pteronyssinus), and Der f1 (D. farinae) are the main species that cause allergic sensitization; Der pl being the predominant species in Europe. During the last decade, Der fl became increasingly more common in certain European countries. Among the European countries investigated in the GA2 LEN skin test study I, house dust mite (HDM) sensitization rates were recorded the highest in the Nordic and Mediterranean countries. The mean sensitization rates to Der $\mathrm{p} 1$ and Der fl in Europe were

Table 1. Standard European prick test panel for inhalant allergens.

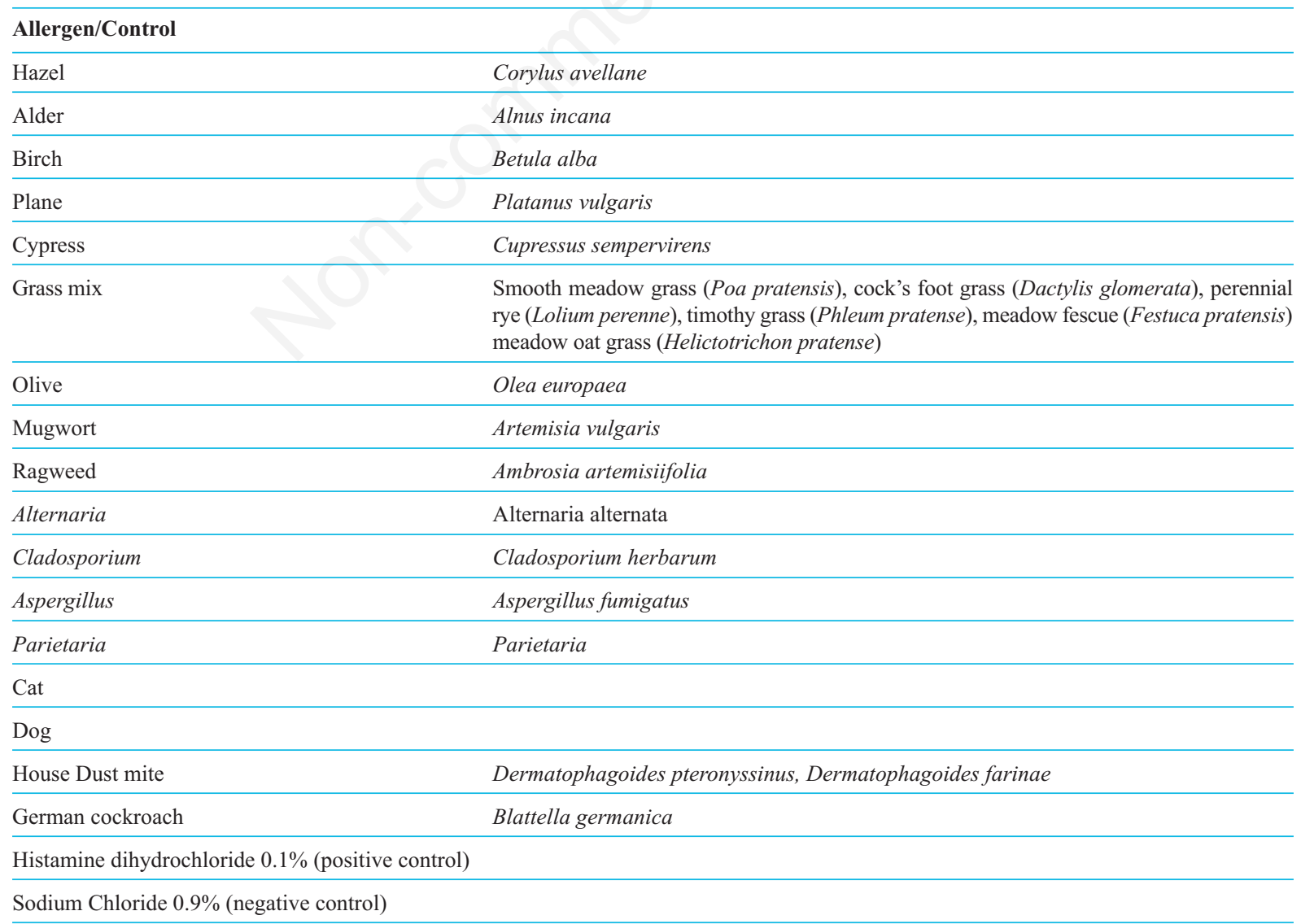


$31.3 \%$ and $28.9 \%$ respectively. ${ }^{17}$ In the populationbased ECRHS sample, the sensitization rate to Der $\mathrm{p} 1$ was $17.8 \%,{ }^{24}$ significantly lower than in the GA ${ }^{2} \mathrm{LEN}$ skin test study I.

Sensitization to both Der p1 and Der f1 was most prominent in Mediterranean countries, such as Portugal (Der p1 68.8\%; Der f1 68.0\%) and Nordic countries such as Denmark (Der p1 51.5\%; Der f1 51.8\%). Central and Western Europe had lower rates of sensitization, for example in Poland (Der p1 22.2\%; Der f1 19.1\%). ${ }^{17}$ The pattern of sensitization to Der p1 and Der f1 were also different in the ECRHS sample, as the highest rates of sensitization amongst the subsample of asthmatic patients for Der p1 was in central Europe and lower rates in northern and southern Europe. ${ }^{25}$

In the US, the HDM sensitization rate was $27.5 \%$, the highest recorded in the Northeast region (Maine, Vermont, New Hampshire, Massachusetts, Connecticut, Rhode Island, New York, New Jersey, and Pennsylvania), $31.6 \%$ and the least prevalent in the Midwest region (Ohio, Illinois, Indiana, Michigan, Wisconsin, Minnesota, Iowa, Missouri, Kansas, Nebraska, North Dakota, and South Dakota). ${ }^{22}$ SPTs cannot determine species-specificity as the allergens from these species of HDM cross react extensively. ${ }^{26}$

ECRHS II provided data of HDM allergen measurements from 22 cities in 10 European countries using 1 standardized protocol. Der $\mathrm{p} 1$ and Der $\mathrm{p} 2$ allergens were detectable in $68 \%$ and $53 \%$ of the samples, respectively. Latitude and longitude affected the distribution of Der p1 and Der f1 allergens. Both HDM allergens are more common with decreasing lat- itude, therefore are more common in southern European countries. Der p1 allergen is more common in western countries when compared to eastern locations and its concentration reduces in low winter temperatures. Longitude and low winter temperature have no effect on Der f1 allergen. Annual relative humidity and altitude were not associated with mite allergen levels. High allergen levels were also identified in households with older mattresses, a lower floor level bedroom and poor ventilation of the bedroom. ${ }^{27}$ A study on NHANES results reached similar results, claiming older homes are associated with positive SPT to HDM and cockroach. ${ }^{22}$ The authors concluded that HDM allergen is highly variable throughout Europe and this could be partly explained by geographic and housing characteristics. HDM allergen reduction is easily achieved by simple modifiable factors such as purchasing a new mattress, increasing ventilation of the bedroom and having a higher bedroom floor. ${ }^{27}$

Cats and dogs are the most prevalent household pets worldwide. The prevalence of animal sensitization, particularly to these animals, has increased in the USA, ${ }^{28}$ Europe, Asian countries ${ }^{29}$ and worldwide. ${ }^{30}$ Nordic countries also had higher sensitization rates to cat and dog allergens as compared to Central/Western and Mediterranean countries. Sensitization to cat allergen was higher in Denmark (49.3\%), Finland (30.4\%), and Hungary (32.5\%) whilst sensitization to dog allergen was higher in Denmark (56.0\%), Finland (36.5\%), and Poland (34.7\%). Austria recorded the lowest sensitization rates to cat $(16.8 \%)$ and dog $(16.1 \%)$ allergens. Belgium and Italy also recorded

Table 2. Standard NHANES III prick test panel for inhalant.

\begin{tabular}{|c|c|}
\hline Allergen/Control & Allergens \\
\hline \multicolumn{2}{|l|}{ Indoor Allergen } \\
\hline House Dust mite & Dermatophagoides pteronyssinus, Dermatophagoides farinae \\
\hline German cockroach & Blattella germanica \\
\hline \multicolumn{2}{|l|}{ Cat } \\
\hline \multicolumn{2}{|l|}{ Outdoor Allergen } \\
\hline Perennial rye & Lolium perenne \\
\hline Bermuda grass & Cynodon dactylon \\
\hline Short ragweed & Ambrosia sp. \\
\hline Russian thistle & Salsola sp. \\
\hline White Oak & Quercus alba \\
\hline Alternaria & Alternaria alternata \\
\hline \multicolumn{2}{|l|}{ Food allergen } \\
\hline \multicolumn{2}{|l|}{ Peanut } \\
\hline Histamine dihydrocl & \\
\hline
\end{tabular}


low sensitization rates to cat $(18.4 \%$ and $21.3 \%$ respectively) and dog (17.8\% and $17.4 \%$ respectively) allergens. ${ }^{17}$ In the USA, allergic sensitization rate among children suffering from atopic asthma living in urban areas was $44.1 \%$ for cat and $21.1 \%$ for dog allergens. ${ }^{31}$ The northeast region of the USA has a greater prevalence of positive skin test response to cat allergen $(20.1 \%)$ as compared to the other regions. ${ }^{32}$

Interestingly, specific cat (Fel d 4) and $\operatorname{dog}(\mathrm{Can} \mathrm{f}$ 1 and Can f 2) allergens exhibit cross-reactivity with other mammalian species such as horses (Equ c 1), cattle (Bos d 2), rabbits (Ory c 1), and rodents. ${ }^{33}$ The sensitization rate to horse dander is underestimated. A study performed in Italy showed higher than expected horse allergen sensitization in urban-dwelling subjects without direct or occupational exposure to horses. ${ }^{34}$ The mean prevalence of allergic sensitization to horse in Italy was of $5.38 \%$, with sensitization rates varying from center to center [northern $(6.31 \%)$, central (5.09\%), and southern (5.24\%) Italy]. ${ }^{35}$ Allergic sensitization to horses can occur through passive transfer. An example of this is from clothing of a person in contact with horses, or also via cross-reactivity through allergens, particularly lipocalins and serum albumin. ${ }^{34,35}$ Thus, several authors, support the inclusion of horse allergen testing in the standard allergen panel, ${ }^{34-37}$ and highly atopic individuals sensitized to cat and dog dander should undergo skin prick testing and specific IgE testing before direct or indirect exposure to horses. ${ }^{34,35}$ Studies have also shown that in cat, dog or horse-allergic children, Can $\mathrm{f} 2$ and Equ c 1 sensitization was more prevalent in severe asthmatics rather than controlled asthmatic individuals. ${ }^{38}$

Sensitization rates to the indoor allergen, $A s$ pergillus fumigatus was generally low, ranging from $0.4 \%$ (Italy) to $6.9 \%$ (Portugal). Portugal had the highest sensitization rate for cockroach (33.4\%), whilst the other European countries showed sensitization rates ranging from $2.1 \%$ in Belgium to $12 \%$ in Germany. ${ }^{17}$ The distribution of positive SPT response to cockroach in the US population represented in NHANES III was $26.1 \%$, with increased prevalence in the Northeast region (27.8\%). ${ }^{22}$ Allergic sensitization to cockroach increases the risk of developing sensitization to crustaceans and HDM as a result of cross-reactivity. ${ }^{39}$

\section{Outdoor allergens}

As expected, Nordic countries have higher sensitization rates to trees typical for the region, such as hazel, alder and birch. Denmark had the most prominent rates of sensitization to hazel (49.4\%), alder (47.0\%) and birch (57.4\%). Central/Western Europe also showed increased sensitization rates to the northern trees with Germany (hazel: $35.9 \%$; alder: $34.8 \%$; birch: $37.6 \%$ ). As latitude decreases, the prevalence of sensitization to the northern trees decreased and were variable. Allergic sensitization to hazel ranges from $7.4 \%$ in Portugal to $11.9 \%$ in France, sensitization to alder ranges from $3.1 \%$ in Italy to $10.4 \%$ in France and birch sensitization ranges from $6.8 \%$ in Portugal to $9.4 \%$ in Italy. Plane and cypress, typical southern trees, had low risk of sensitization throughout Europe.

Countries within the Mediterranean basin have the highest rates of sensitization to olive, ranging from $18.2 \%$ in France to $23.3 \%$ in Italy. Austria and Germany also show high rates of sensitization to olive, $13.3 \%$ and $9.7 \%$ respectively. Sensitization was also noted in the Nordic countries, but far less prevalent. The higher rates of sensitization in countries not sitting on the Mediterranean basin could be explained by the cross-reactivity of the oleaceae pollens, as olive extract tests positive for both olive and European Ash (Fraxinus excelsior), which is increasingly prevalent in most areas of Europe.

The prevalence of sensitization to grasses across Europe was generally high (37.8\%), ranging from $19.5 \%$ in Italy to $69.9 \%$ in Denmark. Hungary has increased rates of sensitization to the grasses, Ambrosia (53.8\%) and Artemisia (44.3\%) as well as both outdoor fungi investigated, Alternaria (18.6\%) and Cladosporium (12.8\%). Artemisia sensitization was increasingly prevalent in Nordic countries [Denmark $(28.3 \%)$ and Finland $(17.6 \%)]$. The highest rates of sensitization to Parietaria were observed in the Mediterranean countries, such as Italy (33.2\%), while Nordic countries show the lowest rates. ${ }^{17}$ In the US population, the highest prevalence to outdoor allergens included rye $(26.9 \%)$ and ragweed $(26.2 \%)$. Rye was more prevalent in the Northeast region (32.2\%) while ragweed was increasingly prevalent in the West (Washington, Oregon, California, Nevada, New Mexico, Arizona, Idaho, Utah, Colorado, Montana, Wyoming, Alaska, and Hawaii) (35\%). The average prevalence of Alternaria in Europe stands at 8.9\%, whilst in the US population at $12.9 \%$. Alternaria was more prevalent in the West region of the US. ${ }^{22}$

Sensitization to alternaria and other fungi has been clearly established to be a risk factor for the development and persistence of asthma ${ }^{40}$ and more importantly, is associated with greater asthma severity, increased hospital admissions and a higher incidence of severe and life-threatening asthma. ${ }^{41,42}$ Airborne fungal spores are often 1000-fold greater than pollen counts with a protracted exposure occurring for months rather than a few weeks, as seen for pollen. Prolonged exposure to Alternaria, as seen with common indoor allergens, such as cat dander and HDM, contribute to the chronicity and severity of asthma in Alternaria sensitive individuals, mitigating (Th)2-type driven inflammatory responses. ${ }^{43}$ A retrospective study conducted in the US showed the adjusted odds ratio of a death caused by asthma occurring on days 
with fungal spore counts of $\geq 1000$ spores $/ \mathrm{m}^{3}$ was 2.2 times higher than when the fungal spore counts were $<1000$ spores $/ \mathrm{m}^{3}{ }^{44} 76 \%$ of severe asthmatics had at least 1 positive mold SPT skin-test positive to $\mathrm{Al}$ ternaria alternata Aspergillus fumigatus, Penicillium notatum, or Cladosporidium herbarum or the yeast Candida albicans compared with $16 \%-19 \%$ of patients suffering from mild to moderate asthma $(\mathrm{P}<0.0001){ }^{42}$

\section{Serological testing}

A large multicenter collaborative study, known as the ECRHS, collected data on serum specific IgE levels to common inhaled allergens and total IgE levels from 25 centers on 3 occasions (baseline, 10- and 20year follow up) over 20 years. ${ }^{45-48}$ Another populationbased study was conducted in the USA, known as NHANES 2005-2006, which collected data regarding total serum IgE levels and asthma prevalence in the US population. ${ }^{23}$

The median total serum IgE in the US population was $40.8 \mathrm{kU} / \mathrm{L}$ (interquartile range, 15.5-114 kU/L) ${ }^{23}$ while that of the European counterpart at baseline was $35.9 \mathrm{kU} / \mathrm{L}$ (interquartile range, $13.2 \mathrm{kU} / \mathrm{L}$ in Iceland to $62.2 \mathrm{kU} / \mathrm{L}$ in France). There were substantial variations in the prevalence of atopy from one area to another, ranging from $16.4 \%$ in Spain to $45.2 \%$ in New Zealand (median 35.6\%) ${ }^{46}$ The prevalence of atopy in the US population was estimated at $42.5 \%{ }^{23}$ The variation in distribution of atopy and total serum IgE levels are independent from each other and are attributed to environmental influence.

Atopy, defined as the presence of at least one positive specific IgE, was assessed by measurements of allergen-specific IgE against a panel of inhalant allergens. A positive test result is defined as a concentration of $0.35 \mathrm{kU} / \mathrm{L}$ or greater of the specific allergen. Both ECRHS ${ }^{46}$ and NHANES 2005-2006 $6^{23}$ used a different allergen battery. ECRHS investigated the presence of specific IgE against Derp p1 (Dermatophagoides pteronyssinus), timothy grass (Phleum pratense), cat dander, Cladosporium herbarum, and a local allergen. Depending on the location of the center involved, specific IgE for a regional allergen was assessed for; Birch (Betula verrucosa) in northern Europe, Parietaria (Parietaria judaica) in southern Europe and ragweed (Ambrosia elatior) in Northern America and Australasia. ${ }^{47}$ The allergen battery used in NHANES 2005-2006 consisted of the following 15 aeroallergens: Alternaria alternata, Aspergillus fumigatus, Bermuda grass (Cynodon dactylon), birch (Betula verrucose), cat dander, cockroach (Blatella germanica), dog dander, house dust mite (Der p1 and Der f1), mouse urine proteins, oak (Quercus alba), ragweed (Ambrosia elatior), rat urine proteins, Russian thistle (Salsola kali), rye grass (Lolium perenne). ${ }^{23}$ In the US study, the same panel was used throughout all states, and local specific IgEs were not tested for.

The level of total IgE is generally reported to decrease with age. During the ECRHS study period, specific $\operatorname{IgE}$ sensitization to HDM and cat, but not grass, showed a significant reduction and appeared more evident in individuals aged 40 years or older. ${ }^{48}$ Similar results were observed in NHANES 2005-2006. The effect of socioeconomic status and ethnicity also effects the total serum IgE level; black and Hispanic race have higher levels of total serum IgE compared to the white race and lower socioeconomic status and low education level is associated with higher total serum IgE levels. ${ }^{49}$ Gender and smoking status also affects serum IgE level outcome, as males and smoking has been reported to increase total serum IgE levels. ${ }^{50,51}$ In both NHANES and ECRHS, bias on the impact of seasonal variation in IgE levels was minimized, patient recruitment and data collection occurred all year round.

\section{Atopy, IgE and asthma}

The prevalence of asthma in the US population represented by NHANES III, tested by SPT, was 5.2\% and the prevalence of atopy, defined as the presence of at least one positive SPT response, was $54.2 \%$. Over half of the asthmatic cases $(56.3 \%)$ were attributed to atopy. Atopic asthma was predominantly found in males and associated with higher education levels and settlement in urban areas. Asthma was strongly associated with all the allergens tested for in the NHANES III, however, after adjustment by all the allergens and the subject characteristics, only cat (29.3\%), Alternaria (21.1\%), and white oak (20.9\%) showed a positive association with asthma. The role of cat exposure in the cause of allergic sensitization and disease remains controversial. According to the NHANES III study, sensitization to cat is a strong risk factor for the development of asthma. ${ }^{22}$

The GA2LEN study proved that the likelihood of atopic asthma increases depending on the number of positive sensitizations. There was an increased prevalence of atopic asthma with $\geq 1$ positive sensitization compared with no positive sensitizations [children aOR $1.96(1.18,3.25)$ and adults aOR 2.29 (1.71, 3.06)], and this increased even further with $\geq 7$ positive sensitizations [children aOR $6.12(2.02,18.54)$ and adults aOR $5.65(4.0,7.97)]{ }^{17,18}$

Data from NHANES 2005-2006, estimated the overall prevalence of asthma in the US population to be $8.8 \%$, with the prevalence of atopy being $42.5 \%$, as defined by 15 specific IgEs. The prevalence of asthma in the US population was higher amongst the 
atopic subjects rather than the non-atopic $(12.9 \%$ and $5.8 \%$ respectively, $\mathrm{P}<0.001$ ), showing a strong association between asthma and atopy [odds ratio 2.41 (95\% CI: 1.94-2.99)]. The total IgE level was significantly higher in the asthmatic population compared to the non-asthmatic subjects (81.1 vs $40.8 \mathrm{kU} / \mathrm{L}$, $\mathrm{P}<0.0001)$. Total IgE closely correlates with asthma risk and with airway responsiveness. However, findings from the NHANES study demonstrate that substantial numbers of non-atopic individuals have asthma which is independent from total $\operatorname{IgE}$ or $\operatorname{IgE}$ specific. ${ }^{23}$ This finding could be explained by two asthma phenotypes associated with low IgE levels: non-atopic asthma and (Th)2-low asthma. Non-atopic asthma is defined by the presence of asthma with the absence of detectable serum specific IgE antibodies and negative SPT to common aeroallergens. (Th)2low asthma is a distinct phenotype, which is characterized by asthma without evidence of (Th)2 and/or eosinophilic inflammation.

The US population attributable risk of asthma symptoms caused by atopy was higher than that reported by the IgE-based ECRHS, as the mean risk was $30.4 \%$. Asthma symptoms caused by atopy varied widely between the ECRHS centers (4-61\%), even within the same country (e.g. for HDM from $7-28 \%$ in Spain; for timothy grass $13-27 \%$ in the United Kingdom). The overall attributable risk of asthma caused by atopy increased depending on a number of variables: wheeze and bronchial responsiveness (42.6\%), physician diagnosis $(45.3 \%)$ and more than 12 asthma attacks in a calendar year (47.6\%). There was a strong correlation of the prevalence of atopy amongst asthmatic patients and the heterogeneity of the attributable fraction of atopy at the center level $(\mathrm{r}=0.91, \mathrm{P}<0.1)$, as well as the prevalence of symptoms of asthma amongst atopic patients $(\mathrm{r}=0.43) .{ }^{52}$

The range of prevalence for the US specific IgE panel ranged from $19.5 \%$ for rye grass to $1.1 \%$ for mouse urine proteins. $62.1 \%$ of the asthmatic US population had $\geq 1$ positive specific IgE. The prevalence of specific IgEs to Der p1 and Der f1 was $18.8 \%$ and $18.5 \%$ respectively. ${ }^{23}$ In the ECRHS, the median HDM prevalence was of $20.3 \%$. The US and ECRHS populations have similar prevalence of specific IgEs to cat. In the ECRHS, the population attributable risk to cat allergen sensitization was of $14.1 \%$ in asthmatic patients. HDM and timothy grass allergen sensitization accounted for $18.2 \%$ and $17.1 \%$ of symptoms in asthma patients. ${ }^{46}$

\section{Conclusions}

The classification of asthma phenotypes and endotypes has already led to novel and successfully targeted existing treatments, such as allergen immunotherapy, which affects IgE reactivity by inducing tolerance to the allergen, biological therapy such as anti-IgE therapy, and biologicals targeting (Th)2 cytokines, such as anti-IL-4, IL-5 and IL-13 treatment.

Immunotherapy affects the humeral activity by increasin allergen specific IgG4 antibodies and decreasin allergen specific IgE antibodies. ${ }^{53,54}$ It also affects regulatory T-cells by increasing IL-10 and IL12 production which downregulates (Th)2 cell-dependent inflammation and suppresses class-switch recombination to $\operatorname{IgE} .{ }^{55}$ Mast cell, basophils and eosinophil activity is downregulated.

Immunotherapy should be considered in pharmacologically well controlled atopic asthma individuals where allergen sensitization is the main driver of clinical symptomatology. ${ }^{53,54}$ According to the GINA 2018 guidelines, allergen immunotherapy is considered as an add-on therapy to achieve better asthma control by reducing symptomatology, medication burden and improving the quality of life. ${ }^{56}$ There are two approaches to immunotherapy, either subcutaneous immunotherapy or sublingual immunotherapy (SLIT). Allergen specific immunotherapy practice patterns differ in the US and Europe. Europeans prescribe SLIT more often, and tend to treat one or two most important sensitizing aeroallergens whilst the US treat polysensitized atopic patients with mixtures including many or most of the sensitizing allergens. ${ }^{57}$ The GINA 2018 recommends immunotherapy with extracts or regimens with proven clinical efficacy demonstrated in clinical trials, such as HDM, grasses and tree allergens. ${ }^{56,58}$

Omalizumab, an anti-IgE biological drug, is indicated in severe atopic asthma with increased total IgE level $(>30 \mathrm{IU} / \mathrm{mL})$ and positive SPTs to perennial aeroallergens and attenuates both the early-phase and late-phase responses to inhaled allergens. ${ }^{59}$ It is a humanized monoclonal antibody directed against the IgE C 83 domain preventing the interaction with the FceRI on mast cells, basophils, eosinophils and dendritic cells. ${ }^{60,61}$ Interestingly, a proof of concept study has shown that the effect omalizumab extends beyond decreasing IgE levels, as it is also beneficial in patients with non-atopic asthma. ${ }^{62}$

Patients with persistent eosinophilia and raised $\operatorname{IgE}$ levels may not necessarily respond to anti-IgE treatment, but may respond to treatments targeting (Th)2 cytokines, such as Anti-IL-5 therapy (mepolizumab, reslizumab and benralizumab) and therapies that inhibit both IL-4 and IL-13 (dupilumab). No targeted therapy is yet available for (Th)2-low asthma, but emerging therapeutic options still in the initial trial stages. Risankizumab, an anti-IL-23, ${ }^{63}$ and low dose macrolide therapy ${ }^{64}$ could offer a potential solution for patients with a (Th)2-low phenotype. 


\section{References}

1. Kay AB. Allergy and allergic disease. N Engl J Med 2001;344:30-7.

2. Braman SS. The global burden of asthma. Chest 2006;130:4S-12S

3. Lotvall J, Akdis CA, Bacharier LB, et al. Asthma endotypes: a new approach to classification of disease entities within the asthma syndrome. J Allergy Clin Immunol 2011;127:355-60.

4. Braido F, Tiotiu A, Kowal K, et al. Phenotypes/endotypes-driven treatment in asthma. Curr Opin Allergy Clin Immunol 2018;18:184-9.

5. Froidure A, Mouthuy J, Durham SR, et al. Asthma phenotypes and IgE responses. Eur Respir J 2016;47:304-19.

6. de Groot JC, Ten Brinke A, Bel EH. Management of the patient with eosinophilic asthma: a new era begins. ERJ Open Res 2015;1:00024-2015.

7. Platts-Mills TA, Woodfolk JA. Allergens and their role in the allergic immune response. Immunol Rev 2011;242: 51-68.

8. Barrett NA, Austen KF. Innate cells and T helper 2 cell immunity in airway inflammation. Immunity 2009;31: 425-37.

9. Li-Weber M, Krammer PH. Regulation of IL4 gene expression by $\mathrm{T}$ cells and therapeutic perspectives. Nat Rev Immunol 2003;3:534-43.

10. Zhu Z, Homer RJ, Wang Z, et al. Pulmonary expression of interleukin-13 causes inflammation, mucus hypersecretion, subepithelial fibrosis, physiologic abnormalities, and eotaxin production. J Clin Invest 1999;103:779-88.

11. Rosenberg HF, Phipps S, Foster PS. Eosinophil trafficking in allergy and asthma. J Allergy Clin Immunol 2007;119:1303-10.

12. Koch S, Sopel N, Finotto S. Th9 and other IL-9-producing cells in allergic asthma. Semin Immunopathol 2017;39:55-68.

13. Durham SR, Craddock CF, Cookson WO, et al. Increases in airway responsiveness to histamine precede allergen-induced late asthmatic responses. J Allergy Clin Immunol 1988;82:764-70.

14. Gauvreau GM, El-Gammal AI, O'Byrne PM. Allergeninduced airway responses. Eur Respir J 2015;46:819-31.

15. Bousquet J, Heinzerling L, Bachert C, et al. Practical guide to skin prick tests in allergy to aeroallergens. Allergy 2012;67:18-24.

16. Heinzerling LM, Mari A, Bergmann KC, et al. The skin prick test - European standards. Clin Transl Allergy 2013;3:3.

17. Heinzerling L, Burbach GJ, Edenharter G, et al. GA(2)LEN skin test study I: GA(2)LEN harmonization of skin prick testing: novel sensitization patterns for inhalant allergens in Europe. Allergy 2009;64:1498-506.

18. Burbach GJ, Heinzerling L, Edenharter G, et al. GA(2)LEN skin test study II: clinical relevance of inhalant allergen sensitizations in Europe. Allergy 2009;64:1507-15.

19. Bryce M, Drews O, Schenk MF, et al. Impact of urbanization on the proteome of birch pollen and its chemotactic activity on human granulocytes. Int Arch Allergy Immunol 2010;151:46-55.

20. Burbach GJ, Heinzerling LM, Rohnelt C, et al. Ragweed sensitization in Europe - GA(2)LEN study suggests increasing prevalence. Allergy 2009;64:664-5.

21. Heinzerling L, Frew AJ, Bindslev-Jensen C, et al. Standard skin prick testing and sensitization to inhalant allergens across Europe - a survey from the GALEN network. Allergy 2005;60:1287-300.

22. Arbes SJ Jr, Gergen PJ, Elliott L, et al. Prevalences of positive skin test responses to 10 common allergens in the US population: Results from the Third National Health and Nutrition Examination Survey. J Allergy Clin Immunol 2005;116:377-83.

23. Gergen PJ, Arbes SJ Jr, Calatroni A, et al. Total IgE levels and asthma prevalence in the US population: Results from the National Health and Nutrition Examination Survey 2005-2006. J Allergy Clin Immunol 2009;124:447-53.

24. Leynaert B, Neukirch C, Kony S, et al. Association between asthma and rhinitis according to atopic sensitization in a population-based study. J Allergy Clin Immunol 2004;113:86-93.

25. Zureik M, Neukirch C, Leynaert B, et al. Sensitisation to airborne moulds and severity of asthma: cross sectional study from European Community respiratory health survey. BMJ 2002;325:411-4.

26. Arbes SJ Jr, Gergen PJ, Elliott L, et al. House dust allergy and immunotherapy. J Allergy Clin Immunol 2005;116:377-83.

27. Zock JP, Heinrich J, Jarvis D, et al. Distribution and determinants of house dust mite allergens in Europe: The European Community Respiratory Health Survey II. J Allergy Clin Immunol 2006;118:682-90.

28. Salo PM, Arbes SJ Jr, Jaramillo R, et al. Prevalence of allergic sensitization in the United States: results from the National Health and Nutrition Examination Survey (NHANES) 2005-2006. Allergy Clin Immunol 2014;134: 350-9.

29. Suh M, Kim HH, Sohn MH, et al. Prevalence of allergic diseases among Korean school-age children: a nationwide cross-sectional questionnaire study. Korean Med Sci 2011;26:332-8.

30. Asher MI, Montefort S, Björkstén B, et al. Worldwide time trends in the prevalence of symptoms of asthma, allergic rhinoconjunctivitis, and eczema in childhood: ISAAC Phases One and Three repeat multicountry cross-sectional surveys. Lancet 2006;368:733-43.

31. Gruchalla RS, Pongracic J, Plaut M, et al. Inner City Asthma Study: Relationships among sensitivity, allergen exposure, and asthma morbidity. J Allergy Clin Immunol 2005;115:478-85.

32. Chan SK, Leung D. Dog and cat allergies: current state of diagnostic approaches and challenges. Allergy Asthma Immunol Res 2018;10:97-105.

33. Matricardi PM, Kleine-Tebbe J, Hoffmann HJ, et al. EAACI Molecular allergology user's guide. Pediatr Allergy Immunol 2016;27:1-250.

34. Liccardi G, D’Amato, Antonicelli L, et al. Sensitization to horse allergens in Italy: a multicenter study in urban atopic subjects without occupational exposure. Int Arch Allergy Immunol 2011;155:412-7.

35. Liccardi G, Salzillo A, Dente B, et al. Horse allergens: an underestimated risk for allergic sensitization in an urban atopic population without occupational exposure. Respir Med 2009;103:414-20.

36. Novembre E, Mori F, Barni S, et al. Should the skin 
prick test to horse be included in the standard panel for diagnosis of respira- tory allergy? J Invest Allergol Clin Immunol 2009;19:237-52.

37. Liccardi G, Salzillo A, Piccolo A, et al. Skin prick test to horse should be included in the standard panel for the diagnosis of respiratory allergy. J Invest Allergol Clin Immunol 2010;20:93-4.

38. Konradsen JR, Nordlund B, Onell A, B et al. Severe childhood asthma and allergy to furry animals: refined assessment using molecular-based allergy diagnostics. Pediatr Allergy Immunol 2014;25:187-92.

39. Wong L, Huang CH, Lee BW. Shellfish and house dust mite allergies: Is the link tropomyosin? Allergy Asthma Immunol Res 2016;8:101-6.

40. Salop M, Arbes SJ Jr, Sever M, et al. Exposure to Alternaria alternata in US homes is associated with asthma symptoms. J Allergy Clin Immunol 2006;118:892-8.

41. Black PN, Udy AA, Brodie SM. Sensitivity to fungal allergens is a risk factor for life-threatening asthma. Allergy 2000;55:501-4.

42. O’Driscoll RB, Hopkinson L, Denning DW. Mold sensitisation allergy is common amongst patients with severe asthma requiring multiple hospital admissions. BMC Pulm Med 2005;5:4.

43. Bush RK, Prochnau JJ. Alternaria-induced asthma. J Allergy Clin Immunol 2004;113:227-34.

44. Targonski PV, Persky VW, Ramekrishnan V. Effect of environmental molds on risk of death from asthma during the pollen season. J Allergy Clin Immunol 1995;95:955-61.

45. Burney PG, Luczynska C, Chinn S, et al. The European Community Respiratory Health Survey. Eur Respir J 1994;7:954-60.

46. Burney P, Malmberg E, Chinn S, et al. The distribution of total and specific serum IgE in the European Community Respiratory Health Survey. J Allergy Clin Immunol 1997;99:314-22.

47. European Community Respiratory Health Survey II Steering Committee. The European Community Respiratory Health Survey II. Eur Respir J 2002;20:1071-9.

48. Amaral AFS, Newson RB, Abramson MJ, et al. Changes in IgE sensitization and total $\mathrm{IgE}$ levels over 20 years of follow-up. J Allergy Clin Immunol 2016;137:1788-95.e9.

49. Litonjua AA, Celedón JC, Hausmann J, et al. Variation in total and specific IgE: effects of ethnicity and socioeconomic status. J Allergy Clin Immunol 2005;115:751-7.

50. Sapigni T, Biavati P, Simoni M, et al. The Po River Delta Respiratory Epidemiological Survey: an analysis of factors related to level of total serum IgE. Eur Respir J 1998;11:278-83.

51. Wuthrich B, Schindler C, Medici TC, et al. IgE levels, atopy markers and hay fever in relation to age, sex and smoking status in a normal adult Swiss population.
SAPALDIA (Swiss Study on Air Pollution and Lung Diseases in Adults) Team. Int Arch Allergy Immunol 1996;111:396-402.

52. Sunyer J, Jarvis D, Pekkanen J, et al. Geographic variations in the effect of atopy on asthma in the European Community Respiratory Health Study. J Allergy Clin Immunol 2004;114:1033-9.

53. Jutel M, Agache I, Bonini S, et al. International consensus on allergy immunotherapy. J Allergy Clin Immunol 2015;136:556-68.

54. Jutel M, Agache I, Bonini S, et al. International Consensus on Allergen Immunotherapy II: Mechanisms, standardization, and pharmacoeconomics. J Allergy Clin Immunol 2016;137:358-68.

55. Ciprandi G, Cirillo I, Fenoglio D, et al. Sublingual immunotherapy induces spirometric improvement associated with IL-10 production: preliminary reports. Int Immunopharmacol 2006;6:1370-3.

56. Global Initiative for Asthma. Global strategy for asthma management and prevention; 2018. Available from: www.ginasthma.com

57. Cox L, Jacobsen L. Comparison of allergen immunotherapy practice patterns in the United States and Europe. Ann Allergy Asthma Immunol 2009;103:451-9.

58. Tari MG, Mancino M, Monti G. Efficacy of sublingual immunotherapy in patients with rhinitis and asthma due to house dust mite. A double-blind study. Allergol Immunopathol (Madr) 1990;18:277-84.

59. Ong YE, Menzies-Gow A, Barkans J, et al. Anti-IgE (omalizumab) inhibits late-phase reactions and inflammatory cells after repeat skin allergen challenge. J Allergy Clin Immunol 2005;116:558-64.

60. Beck LA, Marcotte GV, MacGlashan D, et al. Omalizumab-induced reductions in mast cell Fce psilon RI expression and function. J Allergy Clin Immunol 2004;114:527-30.

61. Lin H, Boesel KM, Griffith DT, et al. Omalizumab rapidly decreases nasal allergic response and FcepsilonRI on basophils. J Allergy Clin Immunol 2004;113:297-302.

62. Garcia G, Magnan A, Chiron R, et al. A proof-of-concept, randomized, controlled trial of omalizumab in patients with severe, difficult-to-control, nonatopic asthma. Chest 2013;144:411-9.

63. NIH: US National Library of Medicine. Efficacy and Safety of BI 655066/ABBV-066 (Risankizumab) in Patients With Severe Persistent Asthma; updated September 13, 2018. Avaialble from: https://www.clinicaltrials.gov/ ct2/show/study/NCT02443298 Accessed: 2 February 2019.

64. Brusselle GG, Vanderstichele C, Jordens P, et al. Azithromycin for prevention of exacerbations in severe asthma (AZISAST): a multicentre randomised doubleblind placebo-controlled trial. Thorax 2013;68:322-9. 